
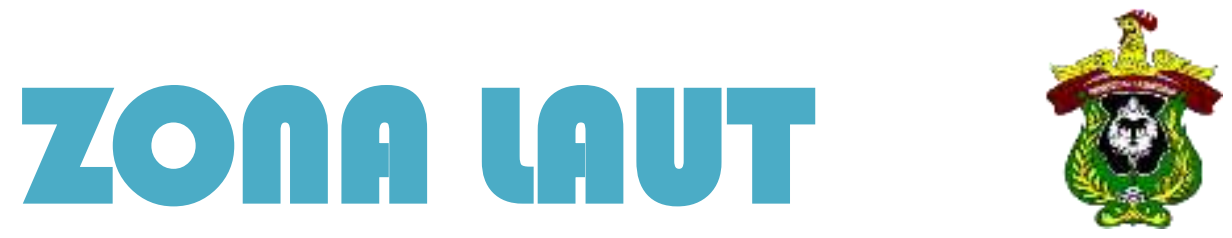

JURNAL INOVASI SAINS DAN TEKNOLOGI KELAUTAN

\title{
PERANCANGAN KONSTRUKSI PROFIL PADA KAPAL GENERAL CARGO DENGAN MENGGUNAKAN METODE SHIP COMPARATIVE
}

\author{
*Rahmahdani Japri \\ Departemen Teknik Kelautan Universitas Hasanuddin \\ *rahmahdanij@gmail.com
}

\begin{abstract}
Abstrak
Kapal general cargo adalah kapal yang mengangkut bermacam-macam muatan berupa barang. Barang yang diangkut biasanya merupakan barang yang sudah dikemas. Ukuran utama kapal didapatkan dengan menggunakan metode pembanding regresi yang didasarkan pada data 2 kapal pembanding yang di dapat dari korea register of shipping (KRS). Pada penelitian ini direncanakan desain konstruksi profil kapal general cargo yang dirancang sesuai dengan ukuran utama kapal yang sesui dengan aturan Rules Biro klasifikasi Indonesia. Dari hasil perencanaan didapat untuk kapal berkapasitas 17000 DWT didapat dimensi kapal dengan length over all (LOA) 153,45 m, length between prependiculars (LBP) 144,24 $\mathrm{m}$, Length on load waterline (LWL) 147,85 m, lebar (B) 25,27 m, tinggi (H) 13,5 m, sarat (T) 9,52 m, kecepatan (V) 14,75 Knot. Metode pembanding ini memudahkan perancangan kapal dengan hasil yang lebih akurat.
\end{abstract}

Kata Kunci : Kapal General Cargo, Konstruksi Profil.

\begin{abstract}
Abstrct
General cargo ship is a ship that carries various kinds of cargo in the form of goods. The goods transported are usually packaged goods. The main size of the ship was obtained using the ship comparative method which was based on the data of the 2 comparison ships obtained from the Korean Register of Shipping (KRS). In this study, a general cargo ship profile construction design is planned which is designed according to the main size of the ship in accordance with the rules of the Indonesian Classification Bureau Rules. From the planning results obtained for ships with a capacity of 17000 DWT obtained ship dimensions with length over all (LOA) $153.45 \mathrm{~m}$, length between prependiculars (LBP) $144.24 \mathrm{~m}$, Length on load waterline (LWL) $147.85 \mathrm{~m}$, width (B) ) $25.27 \mathrm{~m}$, height (H) $13.5 \mathrm{~m}$, draft (H) $9.52 \mathrm{~m}$, speed (V) $14.75 \mathrm{knots}$. This comparison method facilitates ship design with more accurate results.
\end{abstract}

Keywords: General Cargo Ship, Profile Construction.

\section{PENDAHULAN}

\subsection{Latar Belakang}

Kapal general cargo adalah kapal yang mengangkut bermacam-macam muatan berupa barang. Barang yang diangkut biasanya merupakan barang yang sudah dikemas. Dalam pembangunan kapal, berbagai faktor yang harus di perhatikan selain bentuk dan karakteristik badan kapal juga perencanaan kekuatan dan susunan kapal itu sendiri. Susunan kapal yang umumnya terdiri atas badan kapal dan bangunan atas kapal atau rumah geladak yang merupakan konstruksi kapal itu [1].

Pengertian konstruksi khususnya konstruksi kapal adalah komponen-komponen bagian-bagian material kapal yang dibangun sesuai dengan urutan-urutanya serta bagaimana hubungan bagian-bagian dari kapal dan bagaimana cara penyambunganya. Pada umumnya konstruksi kapal terdiri dari badan kapal beserta bangunan atas dan rumah geladak.Selanjutnya penggambaran konstruksi dapat dilakukan dengan tiga cara yaitu: Sistem melintang kapal, Sistem memanjang kapal dan Sistem kombinasi kapal. Penggambaran yang akan dilakukan disini adalah bentuk kapal secara memanjang lengkap dengan bangunan atas kapal, main deck, poop deck, copyright is published under Lisensi Creative Commons Atribusi 4.0 Internasional. 
gambar ambang palka, engine casing, dan double bottom [2][3]. Fungsi dari penggambaran ini adalah antara lain memudahkan pembangunan suatu kapal karena memberikan petunjuk urutan-urutan pembangunan [4] dan cara-cara penyambungan dengan memperlihatkan penampang tiap lajur pelat serta menggambarkan letak dari seluruh lubang atau bukaan kulit pada lambung kapal.

\subsection{Tujuan Penelitian}

Berdasarkan latar belakang di atas maka maksud dan tujuan dari penelitian ini adalah : Mengetahui ukuran utama kapal, Mengetahui ukuran konstruksi yang dapat menahan beban yang dialami oleh kapal dan Mengetahui bentuk penampang kapal baik itu geladak utama, deck house, dan superstruktur, konstruksi bottom dan lain-lain pada kapal.

\section{METODE PENELITIAN}

\subsection{Penentuan Ukuran Utama Kapal (Kapital di Awal Kata)}

Dalam penentuan ukuran utama kapal ini, metode yang digunakan adalah metode perbandingan (comparison method) yaitu dengan memandingkan kapal yang sudah beroperasi.Ukuran utama kapal pembanding adalah sebagai berikut :

Tabel 1. Dimensi utama kapal

\begin{tabular}{lll}
\hline Nama Kapal & Mv. Mataram & \\
\hline Dwt & 17000 & $\mathrm{M}$ \\
Loa & 153.45 & $\mathrm{M}$ \\
Lbp & 144.2 & $\mathrm{M}$ \\
$\mathrm{H}$ & 13.5 & $\mathrm{M}$ \\
$\mathrm{T}$ & 9.52 & $\mathrm{M}$ \\
$\mathrm{B}$ & 25.27 & $\mathrm{M}$ \\
V. & 14.75 & $\mathrm{Knot}$ \\
Volume & 25520,5 & $\mathrm{M}^{3}$ \\
\hline
\end{tabular}

\subsection{Rencana Konstruksi (Profil Contruction)}

Perhitungan konstruksi lambung kapal menggunakan ketentuan Biro Klasifikasi Indonesia untuk menjamin keselamatan kapal dalam beroperasi, maka dalam pemilihan baja kapal yang akan digunakan meliputi kekuatan tarik baja, kelelahan baja kapal, ketahanan terhadap korosi, material baja, dan lain-lain. Berkaitan dengan material baja, baja kapal harus sesuai dengan persyaratan yang diizinkan oleh Biro Klasifikasi Indonesia sebelum digunakan untuk membangun kapal baru. Baja - baja kapal tersebut akan digunakan untuk memperkuat konstruksi badan kapal agar kapal yang akan dirancang memiliki ketahanan terhadap gelombang, tubrukan, maupun deformasi akibat tekanan beban dari kapal itu sendiri. Baja- baja ini berupa profil baja T, profil baja L, maupun kulit baja kapal untuk bagian lambung, alas kapal, deck kapal, dan lain-lain [5].

Dalam tahap penyelesaian perhitungan konstruksi, kekuatan kapal dihitung berdasarkan gaya-gaya dan beban yang bekerja pada setiap komponen lambung kapal. Beban - beban kapal tersebut berpengaruh pada tebal pelat kapal dan pemilihan ukuran profil konstruksi. Tahap demi tahap perencanaan konstruksi lambung kapal adalah sebagai berikut [6]:

a. Perhitungan beban yang bekerja

Persamaan beban geladak cuaca (load on weather decks)

$$
P_{D}=P_{o} \frac{20 \cdot T}{(10+z-T) H} C_{D} \quad\left[K N / m^{2}\right]
$$


Persamaan beban luar sisi kapal (load on ship sides)

$$
P_{S}=10(T-z)+P_{o} \cdot C_{F}\left(1+\frac{z}{T}\right) \quad\left[K N / m^{2}\right]
$$

Persamaan beban luar alas kapal (load on the ship bottom)

$$
P_{B}=10 . T+P_{o} \cdot C_{F} \quad\left[K N / m^{2}\right]
$$

Persamaan beban geladak bangunan atas dan rumah geladak (load on deck structures)

$$
P_{D A}=P_{D} \cdot n \quad\left[K N / m^{2}\right]
$$

Persamaan beban geladak muatan (load on cargo deck)

$$
P_{L}=P_{c}\left(1+a_{V}\right) \quad\left[K N / m^{2}\right]
$$

Persamaan beban alas dalam (load on inner bottom)

$$
P_{i}=9,81 \cdot \frac{G}{V}\left(1+a_{V}\right) \quad\left[K N / m^{2}\right]
$$

Persamaan beban geladak akomodasi (load on accommodation deccks)

Beban geladak akomodasi dan ruang servis

$$
P=3,5\left(1+a_{V}\right) \quad\left[K N / m^{2}\right]
$$

Beban geladak mesin

$$
P=8\left(1+a_{V}\right) \quad\left[K N / m^{2}\right]
$$

b. Perhitungan Konstruksi Pelat

Persamaan pelat alas (Bottom Plate)

$$
t_{b}=1,21 \cdot N_{f} \cdot a \cdot \sqrt{P b x k}+t_{k} \quad[\mathrm{~mm}]
$$

Persamaan Pelat lajur Bilga (Bilga Strake)

$$
B=800+(5 x L B P) \quad[\mathrm{mm}]
$$

Persamaan Pelat lunas (Keel Plate)

Lebar plat lunas tidak kurang dari :

$$
B=800+(5 x L B P) \quad[m m]
$$

Tebal plat lunas pada 0,7. L tengah kapal tidak kurang dari :

$$
t_{f k}=t_{b}+2 \quad[\mathrm{~mm}]
$$

Persamaan Pelat sisi geladak (Side Shell Plate) 


$$
t_{m m}=1,21 \cdot a \cdot\left(P_{s} \cdot k\right)^{0,5}+1,5 \quad[m m]
$$

Persamaan Pelat kulit sisi (Side shell Plating)

$$
t_{s}=1,21 \cdot N_{f} \cdot a \cdot\left(P_{s} \cdot k\right)^{0,5}+t_{k} \quad[\mathrm{~mm}]
$$

Persamaan Pelat Lajur atas (Sheer Strake)

Lebar plat lajur atas tidak kurang dari:

$$
B=800+(5 x L B P) \quad[\mathrm{mm}]
$$

Tebal plat lajur atas secara umum tidak boleh kurang dari:

$$
t=0,5\left(t_{d} \cdot t_{s}\right) \quad[\mathrm{mm}]
$$

Persamaan Pelat Kubu -Kubu (Bullwark)

Tebal plat bulwark tidak boleh kurang dari:

$$
t=0,65(L B P)^{0,5} \quad[\mathrm{~mm}]
$$

Tinggi bulwark tidak boleh kurang dari 1 meter

$$
W=4 . P S \cdot e \cdot l^{2} \quad[\mathrm{~mm}]
$$

c. Perhitungan Konstruksi Alas

Persamaan Pelat alas dalam (inner bottom plate)

$$
T_{i}=1,1 \cdot a \cdot \sqrt{P \cdot K}+t_{k} \quad[\mathrm{~mm}]
$$

Persamaan Pelat Tepi (Margin plate)

$$
t=t_{i}+\left(20 \% \cdot t_{i}\right) \quad[\mathrm{mm}]
$$

Persamaan Penumpu Tengah (center girder)

Tinggi penumpu tengah girder tidak boleh kurang dari:

$$
H d b=350+45 . B \quad[\mathrm{~mm}]
$$

Tebal penumpu tengah $0,7 \mathrm{~L}$ dari tengah kapal

$$
t=\left(\frac{h d b}{100}+1\right) \cdot \sqrt{K} \quad[m m]
$$

Persamaan Penumpu sisi (Side Girder)

$$
t=\left(\frac{h d b}{120}\right) \cdot \sqrt{K} \quad[m m]
$$

Persamaan Wrang plate (Plate Floor)

$$
t=\left(\frac{h d b}{100}-1\right) \cdot \sqrt{K} \quad[m m]
$$


Persamaan Wrang Terbuka (Bracket floor)

Modulus penampang gading alas dan gading balik tidak kurang dari :

$$
W=n . c . a \cdot l^{2} \cdot P \cdot K \quad\left[\mathrm{~cm}^{2}\right]
$$

Persamaan Lightening Hole

$$
r=0,75 \cdot L B P
$$

d. Perhitungan Gading - Gading

Persamaan Jarak antara gading

$$
a=\left(\frac{L B P}{500}\right)+0,48 \quad[m m]
$$

Persamaan Gading utama (Main Frame)

Modulus penampang gading utama tidak boleh kurang dari :

$$
W=n \cdot c \cdot a \cdot l^{2} \cdot P_{s} \cdot f \cdot k \quad\left[\mathrm{~cm}^{2}\right]
$$

Persamaan Gading Besar (Web Frame)

Modulus penampang gading besar tidak boleh kurang dari :

$$
W=0,6 \cdot e \cdot l^{2} \cdot P_{s} \cdot n \cdot k \quad\left[\mathrm{~cm}^{2}\right]
$$

e. Perhitungan Geladak dan Ambang Palka

Persamaan Balok Pelintang geladak (Transverse deck beam) Modulus penampang tidak kurang dari :

$$
W=\text { c.a. } l^{2} \cdot P \cdot K \quad\left[\mathrm{~cm}^{2}\right]
$$

Persamaan Penumpu dan Pelintang geladak ( Girder and transverse deck) Modulus penampang tidak kurang dari :

$$
W=\text { c.e. } l^{2} \cdot P \cdot K \quad\left[\mathrm{~cm}^{2}\right]
$$

Persamaan Balok Palka (Hatcway Beam)

$$
t=10 . a \quad[\mathrm{~mm}]
$$

Persamaan Penegar (Stay)

Modulus penampang tidak kurang dari :

$$
W=4 . e \cdot p d \cdot l^{2} \cdot K \quad\left[\mathrm{~cm}^{2}\right]
$$

Persamaan Ambang palka

Tebal plat ambang palka tidak kurang dari :

$$
t=6,0+0,08333 . L B P \quad[\mathrm{~mm}]
$$

Persamaan Penutup Palka (Hatcway Cover) 
Tebal penutup palka tidak kurang dari :

$$
t=10 . a \quad[\mathrm{~mm}]
$$

Persamaan Lubang Pembebasan (Freeing pots)

Luas lubang pembebasan:

$$
A=0,7 \cdot L B P \quad\left[m^{2}\right]
$$

f. Perhitungan Konstruksi Bukan Kulit

Persamaan Sekat Buritan (Stern Tube Bulkhead)

$$
S b=5 . a \quad[m]
$$

Persamaan Sekat Tubrukan (Collisosn Bulkhead)

$$
L=0,08 . L B P \quad[m]
$$

Persamaan Pelat Sekat (Bulkhead Plating)

$$
t=C_{p} \cdot a \cdot \sqrt{P}+T_{k} \quad[m]
$$

Persamaan Panjang Kamar mesin

$$
L_{K M}=(15-20 \%) . L B P \quad[m]
$$

g. Perhitungan Tangki - Tangki

Tangki bahan Bakar (Fuel oil tank)

$$
\text { Volume }_{\text {Wfo }}<\text { Volume }_{\text {Rancang }}
$$

Tangki minyak diesel (Diesel oil tank)

$$
\text { Volume }_{\text {Wdo }}<\text { Volume }_{\text {Rancang }}
$$

Tangki minyak pelumas (Lubrican oil tank)

$$
\text { Volume }_{\text {Wlub }}<\text { Volume }_{\text {Rancang }}
$$

Tangki air tawar (Fresh water tank)

$$
\text { Volume }_{\text {Wpm }}<\text { Volume }_{\text {Rancang }}
$$

Tangki Ballast (Ballast tank)

$$
\text { Volume }_{W b}<\text { Volume }_{\text {Rancang }}
$$

\section{HASIL DAN PEMBAHASAN}

Pembahasan hasil dari perancangan konstruksi profil pada kapal cargo dilakukan dengan menghitung perancangan yang sesuai dengan aturan Rules Biro Klasifikasi Indonesia. maka dirincikan dalam table di bawah. 
Tabel 1. Hasil Perhitungan Perancangan Konstruksi profil Kapal General Cargo

a. Beban yang bekerja pada kapal

Beban Geladak cuaca (load on weather decks)

Beban luar sisi kapal (load on ship sides)

26,025

106,291

Beban luar alas kapal (load on the ship bottom)

Beban geladak bangunan atas dan rumah geladak

(load on deck structures)

Beban geladak muatan (load on cargo deck)

Beban alas dalam (load on inner bottom)

Beban geladak akomodasi (load on

accommodation deck)

Beban geladak akomodasi dan ruang servis :

Beban geladak mesin :

b. Konstruksi pelat

Pelat alas (Bottom Plate)

Pelat lajur Bilga (Bilga Strake)

Pelat lunas (Keel Plate)

Lebar plat lunas tidak kurang dari :

Tebal plat lunas pada 0,7. L tengah kapal tidak

kurang dari :

Pelat sisi geladak (Side Shell Plate)

Pelat kulit sisi (Side shell Plating)

Pelat Lajur atas (Sheer Strake)

Lebar plat lajur atas tidak kurang dari:

Tebal plat lajur atas secara umum tidak boleh

kurang dari:

Pelat Kubu-Kubu (Bullwark)

Tebal plat bulwark tidak boleh kurang dari:

Tinggi bulwark tidak boleh kurang dari 1 meter

c. Konstruksi alas

Pelat alas dalam (inner bottom plate)

Pelat Tepi (Margin plate)

Penumpu Tengah (center girder)

Tinggi penumpu tengah girder tidak boleh kurang

dari:

Tebal penumpu tengah $0,7 \mathrm{~L}$ dari tengah kapal

Penumpu sisi (Side Girder)

Wrang plate (Plate Floor)

Wrang Terbuka (Bracket floor)

Modulus penampang gading alas tidak kurang dari :

Modulus penampang gading balik tidak kurang

dari :

Lightening Hole

d. Gading Gading

Jarak antara gading

Gading utama (Main Frame)

Modulus penampang gading utama tidak boleh

kurang dari :

Gading Besar (Web Frame)

Modulus penampang gading besar tidak boleh

kurang dari :

e. Geladak dan Ambang palka

Balok Pelintang geladak (Transverse deck beam)

Modulus penampang tidak kurang dari :
120,888

40,728

58,799

82,403

3,973

9,081

9,482

1521

1521

10,40

8,984

8,985

1521

10,35

7,805

765,29

7,49

8,99

1487

15,87

12,39

13,87

54,04

100,91

0,108

0,77

993,33

3331,108

598,581 $\mathrm{cm}^{3}$

$\mathrm{cm}^{3}$

$K / m^{2}$

$K / m^{2}$

$K / m^{2}$

$K / m^{2}$

$K / m^{2}$

$K / m^{2}$

$K / m^{2}$

$K / m^{2}$

$\mathrm{mm}$

$\mathrm{mm}$

$\mathrm{mm}$

$\mathrm{mm}$

$\mathrm{mm}$

$\mathrm{mm}$

$\mathrm{mm}$

$\mathrm{mm}$

$\mathrm{mm}$

$\mathrm{cm}^{3}$

$\mathrm{mm}$

$\mathrm{mm}$

mm

$\mathrm{mm}$

$\mathrm{mm}$

$\mathrm{mm}$

$\mathrm{cm}^{3}$

$\mathrm{cm}^{3}$

$\mathrm{mm}$

m

$m m$ 
Penumpu dan Pelintang geladak ( Girder and transverse deck)

Modulus penampang tidak kurang dari :

$\begin{array}{lc}1795,74 & \mathrm{~mm} \\ 3011,727 & \mathrm{~mm} \\ 20,997 & \mathrm{~mm} \\ 18,01 & \mathrm{~mm} \\ 7,684 & \mathrm{~mm} \\ 7065,8 & \mathrm{~mm} \\ & \\ 2,305 & \mathrm{~m} \\ 11,536 & \mathrm{~m} \\ 10,69 & \mathrm{~m}\end{array}$

Balok Palka (Hatcway Beam)

Penegar (Stay)

Modulus penampang tidak kurang dari :

Ambang palka

Tebal plat ambang palka tidak kurang dari :

Penutup Palka (Hatcway Cover)

Tebal penutup palka tidak kurang dari :

Lubang Pembebasan (Freeing pots)

Luas lubang pembebasan:

f. Konstruksi bukan kulit

Sekat Buritan (Stern Tube Bulkhead)

Sekat Tubrukan (Collisosn Bulkhead)

Pelat Sekat (Bulkhead Plating)

g. Tangki - tangki

Tangki bahan Bakar (Fuel oil tank)

Berat bahan bakar :

19,2037

20,21

Volume Wfo :

61,23

Ton

Volume rancang:

$20,21<61,23$

$m^{3}$

Volume Wfo < Volume rancang

Tangki minyak diesel (Diesel oil tank)

Berat air tawar :

276,77

Volume Wdo:

3,84

Volume rancang :

203,73

$m^{3}$

Volume Wdo < Volume rancang

Tangki minyak pelumas (Lubrican oil tank)

3,84 $<203,73 \quad$ (Memenuhi)

Berat minyak pelumas :

0,013

0,0352

Volume Wlub :

8,02

Volume rancang :

Volume Wlub < Volume rancang

Tangki air tawar (fresh water tank)

$0,0352<8,02$

(Memenuhi)

Berat air tawar :

276,8

Volume Wpm :

Volume rancang :

Volume Wpm < Volume rancang

273,1

401,44

Ton

$m^{3}$

$m^{3}$

Tangki Ballast (Ballast tank)

Berat Ballast :

273,1<401,44 (Memenuhi)

Volume $\mathrm{Wb}$ :

1360

1326

Volume rancang :

4605

Volume $\mathrm{Wb}<$ Volume rancang

$1326<4605 \quad$ (Memenuhi)

Berdasarkan tabel perhitungan perancangan konstruksi profil kapal general cargo di atas maka dapat digambarkan konstruksi kapal MV. Mataram sebagai berikut. 


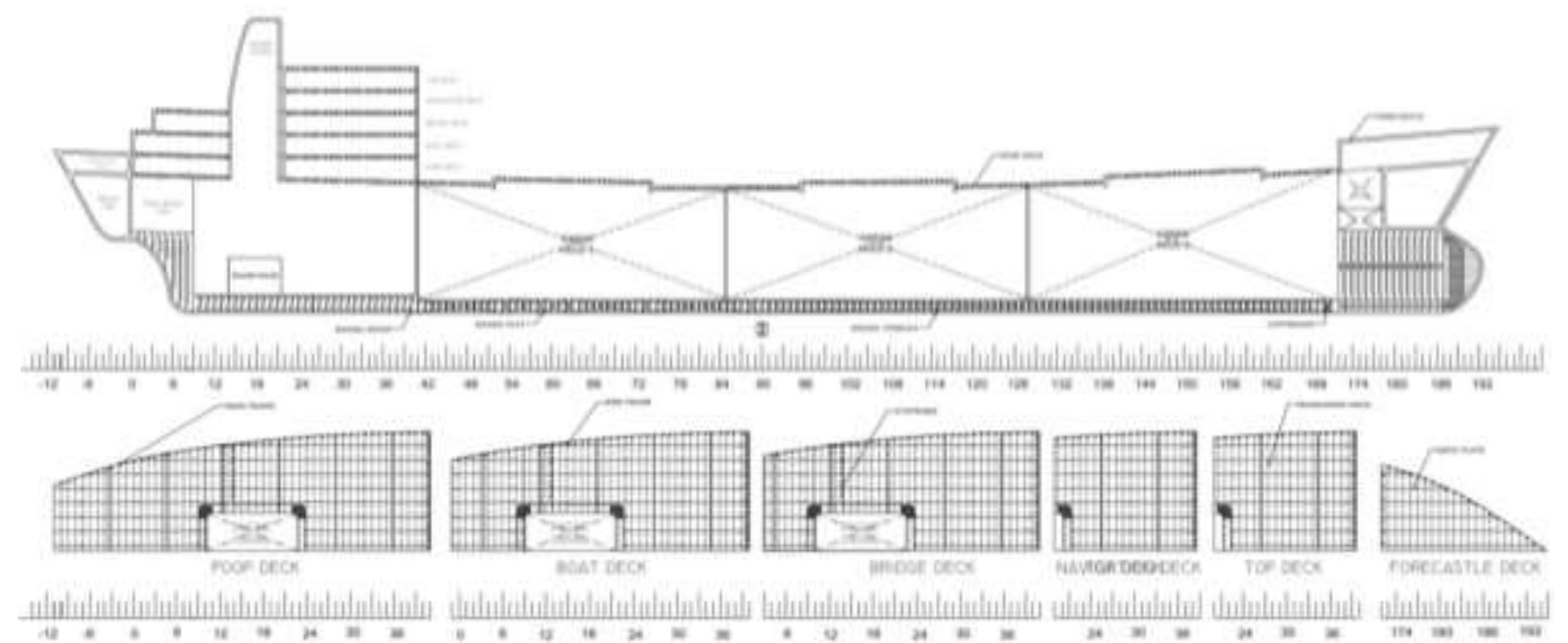

Gambar 1. Konstruksi profil kapal general cargo bagian rumah gladak kapal
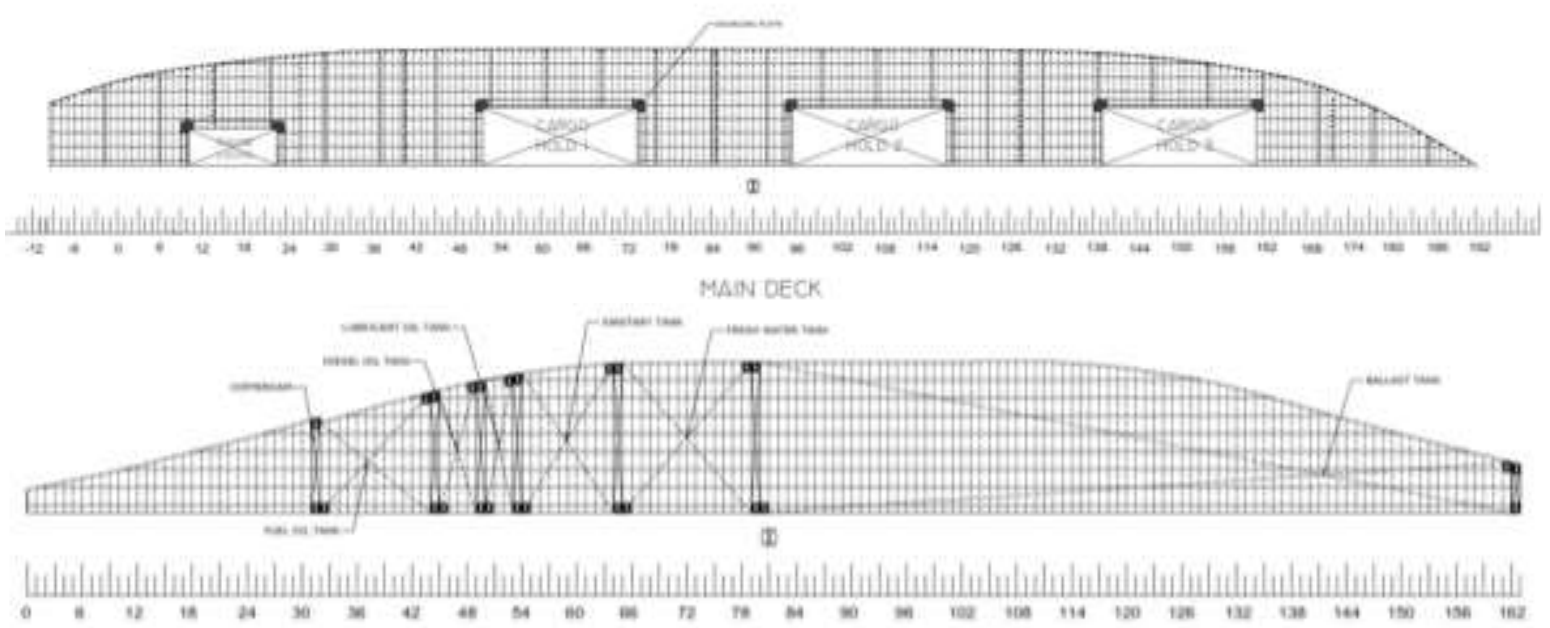

DOUBLE BOTTOM

Gambar 2. Konstruksi profil kapal general cargo bagian main deck dan double bottom

\section{KESIMPULAN}

Konstruksi secara umum berarti komponen - komponen bangunan yang mendukung suatu bangunan yang mendukung suatu desain. Konstruksi kapal merupakan susunan komponen - komponen pada bangunan kapal yang terdiri dari bagian badan kapal beserta bangunan atas dimana terbagi atas komponen konstruksi yang letaknya arah memanjang dan melintang. Dari hasil perhitungan diperoleh bahwa konstruksi profil dan volume tangki yang dipili sudah memenuhi standar BKI yang digunakan.

\section{DAFTAR PUSTAKA}

[1] Harvald phoels "Ship design and ship theory," University of Hannover.

[2] Sumarjono,WA. "Konstruksi kapal I dan II," Fakultas Teknologi kelautan Jurusan Perkapalan ITS, Surabaya.

[3] A. Ma'ruf, D. Paroka, dan H. Palippui, "Analisa Pengaruh Jumlah Muatan Terhadap Beban Sloshing Tangki Pada Kapal Tanker Dengan Metode Numerik", zonalaut, vol. 2, no. 1, hlm. 7-13, Mar 2021..

[4] Rawson. Basic Ship and Theory 1966 : Lonhman Scientific and Technical.

[5] Thomas. Gilmen, Introduction to Naval Architecture, London and F.N.Spon : Great Britania 1982.

[6] Biro Klasifikasi Indonesia (1996) "Rule for the classification and Construction of Sea going Ship," Volume II 